\title{
Editorial NorDiNa 1/2017
}

Welcome to the first issue of NorDiNa this year. In this issue of NorDiNa, we present six research articles, one contribution to the curriculum development section, as well as two recent $\mathrm{PhD}$ dissertations from the Nordic science education community.

The article by Per Sund and Louise Sund is entitled " "What if everybody is making a mistake" - Barriers for teacher's assessment of student's practical abilities during a national test". The authors argue that science teachers regard practical work as important and as something which help students to learn science. Besides theoretical knowledge, practical work is considered to be an integral part of science education. This implies that in addition to theoretical science tests, there is a need to find new ways of assessing students' practical work. The authors' empirical case study investigates two secondary school science teachers' assessments of students in three separate groups in the practical part of a Swedish national test in chemistry. The results show that individual and independent assessments of student's practical abilities are difficult due to the social interactions that take place and physical sources of error that occur in this type of laboratory setting. The results are discussed in relation to how teachers' assessments of students' practical abilities can be conducted and made more equal and fair.

"Semantic waves - discursive mobility in students' small group discussions" is the title of the contribution by Pia Nygård Larsson and Anders Jakobsson. The article analyses exploratory talk, and use of language when students collaboratively discuss a science assignment. The aim is to develop an analytical tool that can facilitate understanding and visualization of students' language use. The concepts of discursive mobility and semantic waves constitute the starting point in the analysis and the students' discussions are explored by using the concepts of semantic gravity and semantic density. The results display that all of the students' conversations contain a certain degree of discursive mobility. However, differences exists in how the conversations move between everyday and scientific languages and in terms of how successful the students are to formulate a specific subject language. In some conversations, everyday expressions become a productive resource and a bridge to a more scientific language.

Magnus Oskarsson, Nina Eliasson and Karl Göran Karlsson's article is entitled "Everyday life context in grade 4 or knowledge without context in grade 8". This study compares Swedish pupils' results for individual tasks in science in TIMSS 2011 with an average score of countries in the EU or OECD. The items are classified by whether they are put in a context and if they ask for school specific knowledge or if they could be solved with knowledge from sources outside school. The authors find that a large proportion of the items in grade 4 are linked to a context and to students' everyday lives, which explains the good results for the younger students. They argue that few items in grade 8 are of interest for the students or linked to students' daily lives and on these items Swedish students often perform below average for the EU/OECD, which contributes to the less favorable outcome in grade 8 . The weak development of knowledge between grades 4 and 8 demonstrated by TIMSS results suggests that formalized science classes in school do not reach the students and it points to the need for a clearer connection to students' interests and experiences. 
In their article entitled "Vocational students' meaning-making in school science - negotiating authenticity through multimodal mobile learning”, Mette Nordby, Erik Knain, and Guðrún Jónsdóttir present a qualitative study focusing vocational students' meaning making in school science when introduced to teaching combining classroom lessons with an excursion to a district heating plant, using mobile phones for documentation. The background of the study is the fact that many vocational students in upper secondary school in Norway find little meaning in school science. By offering the students teaching in a real life vocational facility, the authors found that the students engaged in the related school science subject matter, and that the students' use of mobile phones connected the two learning venues. According to the authors, the learning potential arising when the mobile learning bridged the two learning venues overshadowed the possible pitfalls of using smartphones.

In their article "Eight Norwegian teachers' understanding of- and experience with inquiry-based science education and "The budding researcher» nine years after the implementation of the Norwegian national curriculum “Kunnskapsløftet” (LK-06)” Kåre Haugan, Sigrid Gutvik Korssjøen and Kjerstin Skarpnes argue that improved learning by implementation of inquiry-based science education (IBSE) has been well documented. Eight Norwegian secondary school teachers associated the term IBSE with problem solving, good student dialogues, experiments and practical work. They rarely implemented "full" IBSE in their teaching practices even though this is well anchored in the Norwegian national curriculum. In order to promote and increase the implementation of IBSE in secondary school science teaching, two strategies might be good to pursue; increased time resources to teach science in the Norwegian school and introduction of IBSE-focused teacher training programs.

Susanne Thulin and Laila Gustavsson have conducted research on how pre-school teachers during an in-service training period develop theoretical knowledge about focusing content when planning for teaching science in pre-school. In their article "Teachers' ways of seeing teaching and science as content in pre-schools", variation theory is used for analysis as well as for planning for teaching in pre-school. The theory can be described in terms of learning object, critical aspects, discernment, simultaneity and differences. 30 pre-school teachers from nine different municipalities participated in the project. The empirical material consisted of a questionnaire which the pre-school teachers answered in the beginning and in the end of the training period and of group reports. The results of the study can, according to the authors, be discussed as a number of critical aspects in relation to teachers' learning as: ways of understand the concept of variation, to discern the object of learning and to discern shared space of learning.

In the curriculum development section, Merete Økland Sortland, Tarja Irene Tikkanen, Marianne Presthus Heggen, Kari Holter, Guri Langholm, Stig Broström, Karen Bollingberg, Birgitte Damgaard, Thorleif Frøkjær, Laila Gustavsson, Sigve Ladstein, Kari Grutle Nappen, Kristín Norðdahl, Heidi Harju-Luukkainen, Eva Staffans, Susanne Thulin present a paper with the title "Quality of Kindergarten Teacher Training in regard to Science: a Joint Nordic Approach". The contribution describes a new joint Nordic study module consisting of a theoretical framework, a case study and reflection talk, in natural science for the kindergarten teacher education. The module has been developed through an interdisciplinary collaboration in the Nordplus network: Learning of science concepts by kindergarten children: Nordic study module for the kindergarten teacher education (NATGREP), with science and quality in the kindergarten teacher education in focus.

In this issue of NorDiNa, we also present two new PhD dissertations from the Nordic science education community.

We hope you enjoy your reading!

Are Turmo \& Carl-Johan Rundgren 